\title{
Population Dynamics of the Caroun Croaker Johnius carouna (Cuvier, 1830) in Coastal Fishing Ground in the Middle Gulf of Thailand
}

\author{
Amonsak SAWUSDEE ${ }^{*}$ and Jantira RATTANARAT \\ Division of Marine Science, School of Science, Walailak University, \\ Nakhon Si Thammarat 80160, Thailand
}

('Corresponding author's e-mail: samonsak@wu.ac.th)

Received: 16 October 2020, Revised: 12 January 2021, Accepted: 19 February 2021

\begin{abstract}
The stock status of coastal species is currently of high concern among the people. In the Gulf of Thailand, Croakers are important economic species commonly found in the coastal fishing ground, especially in Nakhon Si Thammarat province. The population dynamics of the Caroun croaker, Johnius carouna (Cuvier, 1830), was investigated using length-frequency distribution data collected from February 2019 to January 2020. The length-weight relationship equation suggested that J. carouna is isometric growth. The asymptotic total length $\left(\mathrm{L}_{\infty}\right)$ and curvature growth $(\mathrm{K})$ were $22.28 \mathrm{~cm}$ and 0.72 year ${ }^{-1}$, respectively. Based on $\mathrm{L}_{\infty}$ and $\mathrm{K}$, the total mortality rate during the study period was estimated at 3.66 year $^{-1}$; natural mortality and fishing mortality rates were estimated at 1.62 and 1.74 year $^{-1}$, respectively. While biological data revealed that matured size was $15.3 \mathrm{~cm}$, the fishing data suggested that the average catch size $(15.12 \mathrm{~cm})$ was slightly smaller than the matured size. The exploitation rate was 0.52 year $^{-1}$. The result from this research suggests that current fishing pressure is slightly high. This study suggested that increasing catch size by increasing mesh size of gillnets seems to be a better solution to improve $J$. carouna stock in Thasala fishing ground in the future.
\end{abstract}

Keywords: Croaker population, Local fishery, Coastal species, Fishery management

\section{Introduction}

Croakers or drums are important fishery resources in the shallow warm seas and estuaries of the world. The Caroun croaker (Johnius carouna) is one of the coastal fish widely distributed along shallow coastal waters. Based on catch composition, this fish species is dominantly observed from the north to southern China to the West India, especially Gulf of Thailand [1]. Johnius carouna is euryhaline and can be found in freshwater, brackish-water and marine habitats but frequently occurs in coastal zone because they serve as the main feeding ground for J. carouna, which feeds on small fish, crustaceans, worms and insects [1]. As the stock of most target economic species is overfishing and rare [2], the next economic species such as croakers are subsequent fishing target. Although the current state of $J$. carouna has not yet been evaluated and scientific support for improving stock status is currently limited, demand and fishing pressure on this species is thought to have increased. This is because $J$. carouna became dominant in numbers when considering catch composition from coastal fishing ground.

One of the important fishing grounds of J. carouna in the Gulf of Thailand is Thasala coastal area, Nakhon Si Thammarat province. Several types of bottom gillnets can catch croakers in this zone, such as croakers gillnet, shrimp gillnet, local mackerel gillnet, etc. The fishermen in this zone have experienced a decrease in J. carouna population, which resulted in a limited catch. This is possibly due to the overfishing of this species. In Thasala fishing ground, fishers applied restored methods e.g., constructing artificial fish habitat to increase fish abundance in the fishing area. 
Recently, there is no established information on the biology and population dynamics of J. carouna in Thai waters. The population dynamics and size at maturation of $J$. carouna in Thasala coastal area are desired to support appropriate fisheries management. Therefore, this paper presents the population parameters and the relative yield per recruit of J. carouna. The findings are necessary to understand stock situation and can be applied for improving Caroun croaker stock in coastal zone area, Southern Thailand.

\section{Materials and methods}

Three sampling sites were selected (Figure 1), and fixed by using the Garmin-GPSmap 76CSx. The field samplings were conducted from February 2019 to January 2020. Samplings were conducted monthly during the spring-tide period in general coastal fishing ground within 5,000 $\mathrm{m}$ from coastal line. The fish samplings were conducted by using 3 dominant gillnets caught Croaker, which are drum gillnet, shrimp gillnet and mackerel gillnet. Every type of sampling gears was operated during day time (7 am - $2 \mathrm{pm}$ ). Three sampling stations were designed to represent Thasala coastal area, and 3 replications for each gear were collected at each station. Fish samples were packed and kept in ice then brought to Walailak University about $20 \mathrm{~km}$ from the coastal line. Species identification was made, and J. carouna in the subsamples were measured in terms of total length (TL, to the nearest $0.1 \mathrm{~cm}$ ) and weighted (to the nearest $0.1 \mathrm{~g})$.

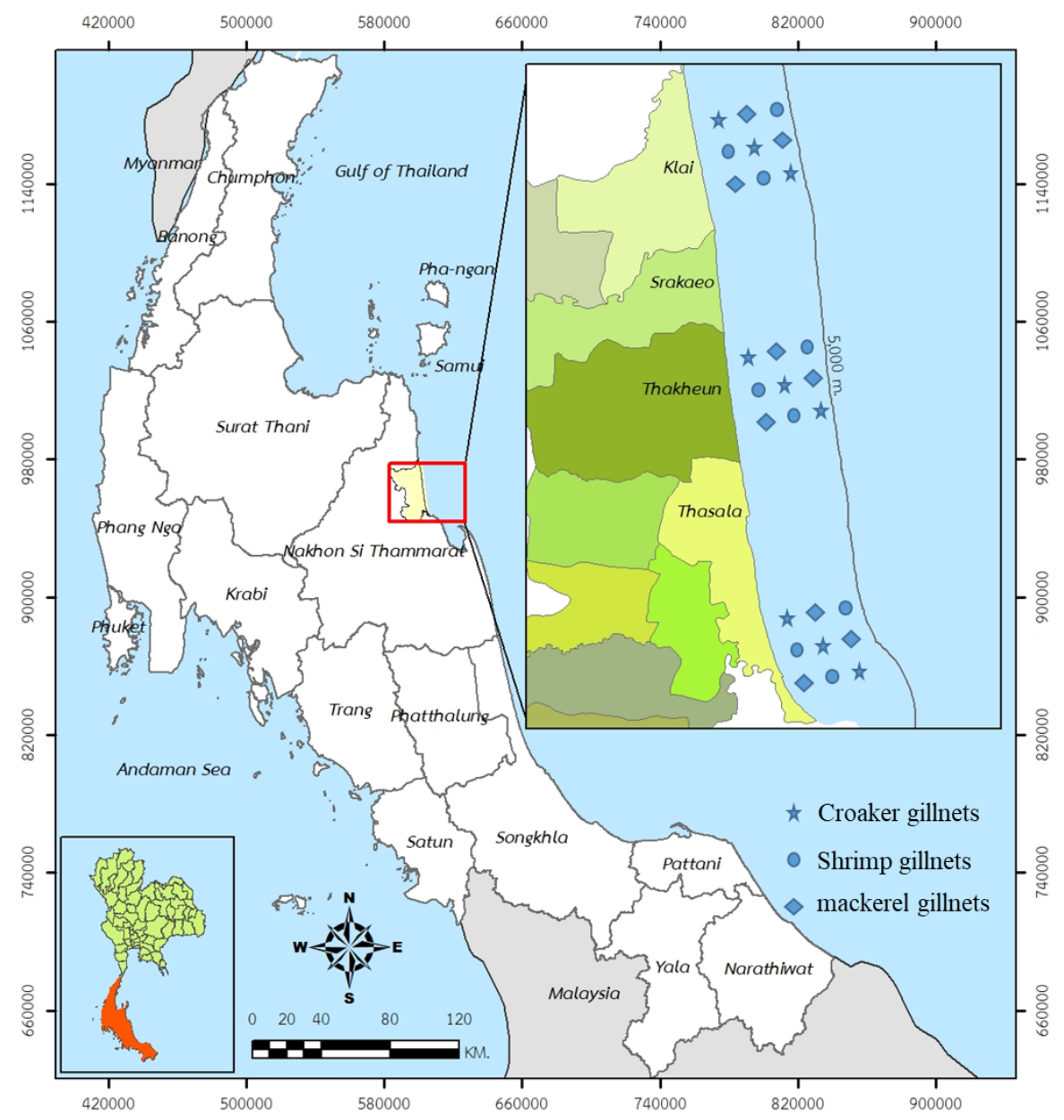

Figure 1 Thasala coastal area and sampling sites. 


\section{Data analysis}

Length-weight relationship was calculated by fitting power function (Eq. (1)) [3].

$\mathrm{W}=\mathrm{aL}^{\mathrm{b}}$

where $W$ represents weight (g); L represents total length $(\mathrm{cm}), a$ is the intercept (condition factor) and $b$ is the slope (growth coefficient). The constraints $a$ and $b$ and the coefficient of determination $\left(R^{2}\right)$ were calculated using power regression to show the correlation level of the relationship. Test of $b$ as 3 was also performed to confirm the isometric growth. Length frequency data (LFD) was classified into $0.5 \mathrm{~cm}$ intervals. The "FiSAT II" (FAO-ICLARM Stock Assessment Tool) software [4] was used as a tool for predicting parameters for the von Bertalanffy growth formula (Eq. (2)):

$\mathrm{L}_{\mathrm{t}}=\mathrm{L}_{\infty}\left[1-\exp \left(-\mathrm{K}^{\left(\mathrm{t}-\mathrm{t}_{0}\right)}\right)\right]$

where, $\mathrm{L}_{\mathrm{t}}$ is the predicted length at age $\mathrm{t}(\mathrm{cm}), \mathrm{L}_{\infty}$ is the asymptotic length $(\mathrm{cm}), \mathrm{K}$ is the curvature parameter $\left(\right.$ year $^{-1}$ ) and $t_{0}$ is the "age" at which $\mathrm{L}_{t}=0$ [5]. $\mathrm{L}_{\infty}$ and $\mathrm{K}$ were estimated as described by [6] and $\mathrm{t}_{\mathrm{o}}$ was therefore obtained from the empirical equation (Eq. (3)) [7]:

$\log 10\left(-\mathrm{t}_{0}\right)=-0.3922-0.2752 \log 10\left(\mathrm{~L}_{\infty}\right)-1.038 \log 10(\mathrm{~K})$ (4) $[8]$ :

Phi-prime value $(\varnothing)$ is applied for validation of growth parameters estimation that obtained from Eq.

$\varnothing=\log 10(\mathrm{~K})+2 \log 10\left(\mathrm{~L}_{\infty}\right)$

Maturity size of $J$. carouna was estimated by using logistic function model (Eq. (5)) [10].

$P_{L}=\frac{1}{1+e^{(a+b L)}}$

where, $\mathrm{P}_{\mathrm{L}}$ is the proportion of matured fish per total fish, $\mathrm{L}$ is mid-length of size class interval, $\mathrm{a}$ and $\mathrm{b}$ are constants.

The natural mortality rate (M) was estimated from the empirical linear relationship model of Pauly (1980), using an average surface water temperature (T) in Thasala coastal zone of $30.0^{\circ} \mathrm{C}$ (Eq. (6)).

$\log 10(\mathrm{M})=-0.0066-0.279 \log 10\left(\mathrm{~L}_{\infty}\right)+0.6543 \log 10(\mathrm{~K})+0.463 \log 10(\mathrm{~T})$

The LFD were converted to age - frequency distribution via Eq. (7):

$\mathrm{t}=\left[\left(\frac{1}{\mathrm{~K}}\right) \ln \left(\frac{\mathrm{L}_{\infty}}{\mathrm{L}_{\infty}-\mathrm{L}_{\mathrm{t}}}\right)\right]+\mathrm{t}_{0}$

The total mortality rate $(Z)$, was then estimated from the length-converted catch curve in which the natural logarithms of the numbers in each age class were plotted against age [10,11]. The fishing mortality rate $(\mathrm{F})$ was calculated as $\mathrm{Z}-\mathrm{M}$ and the exploitation rate $(\mathrm{E})$ was then estimated as $\mathrm{F} / \mathrm{Z}$. The recruitment pattern was figured out through LFD and incorporated the parameters from VBGF. Probabilities of capture were estimated from the selection of LFD. The analyses of the $Y^{\prime} / R$ were performed by the FiSAT II program. The input parameters of $Y^{\prime} / R$ model are the asymptotic length $(L \infty)$, the curvulture parameter $(\mathrm{K})$ and natural mortality rate $(\mathrm{M})[12]$. 


\section{Results and discussion}

A total number of 1,232 individuals (513 males and 719 females) were analyzed. Length range of $J$. carouna were $8.0-22.5 \mathrm{~cm}$ and average length was $15.7 \pm 1.50 \mathrm{~cm}$. Weight range of fish samples were $9.4-150.1 \mathrm{~g}$. and the average weight was $49.6 \pm 15.9 \mathrm{~g}$. This data showed that various sizes of collected fish were included as this was a requirement of input data for estimating crucial parameters related to population dynamics.

The length-weight relationship of male, female and total $J$. carouna (Eqs. (8) - (10)) had high $\mathrm{R}^{2}$ value $(0.89,0.84$ and 0.87 , respectively) and the exponent was not significantly different from 3 ( $p$-value $>0.05)$.

$\mathrm{W}=0.0111 \mathrm{~L}^{3.036}$

$\mathrm{W}=0.0151 \mathrm{~L}^{2.9332}$

$\mathrm{W}=0.0117 \mathrm{~L}^{3.0223}$

From constructed equations, it is assumed that males and females $J$. carouna are an isometric species (i.e. the increase in weight is same proportional to the length; Figure 2). Length-Weight relationship of fish and shellfish have been studied widely in all parts of the world by several researchers because it is an initial study for population dynamics study that is very important information supporting fishery management plan [13]. Different values for the exponent coefficient (b) for differed fish species and locations related to variation of ecological conditions have been recorded [14]. Previously, a pioneer researcher pointed out that the exponent coefficient (b) computed from length and weight relationship is usually 3 [15]. However, later researchers [16] argued that the b value is very close to 3 but varies from 2.5 - 3.5. These statements could be supported by the previous work carried out for various other Croaker species for example, 3.034 for Otolithes cuvieri in Bombay waters of India [17], 3.030 for Johnius dussumieri in Beibu Gulf of China [18], 3.100 for Nibea soldado in Sibuti River, Sarawak of Malaysia [19], 2.630 for Otolithes ruber in southwestern coast of Taiwan [20], 3.069 for Daysciaena albida in Narreri Lagoon of Pakistan [21]. Therefore, this b value cannot be simply compared for consistency as these are different species and habitats.

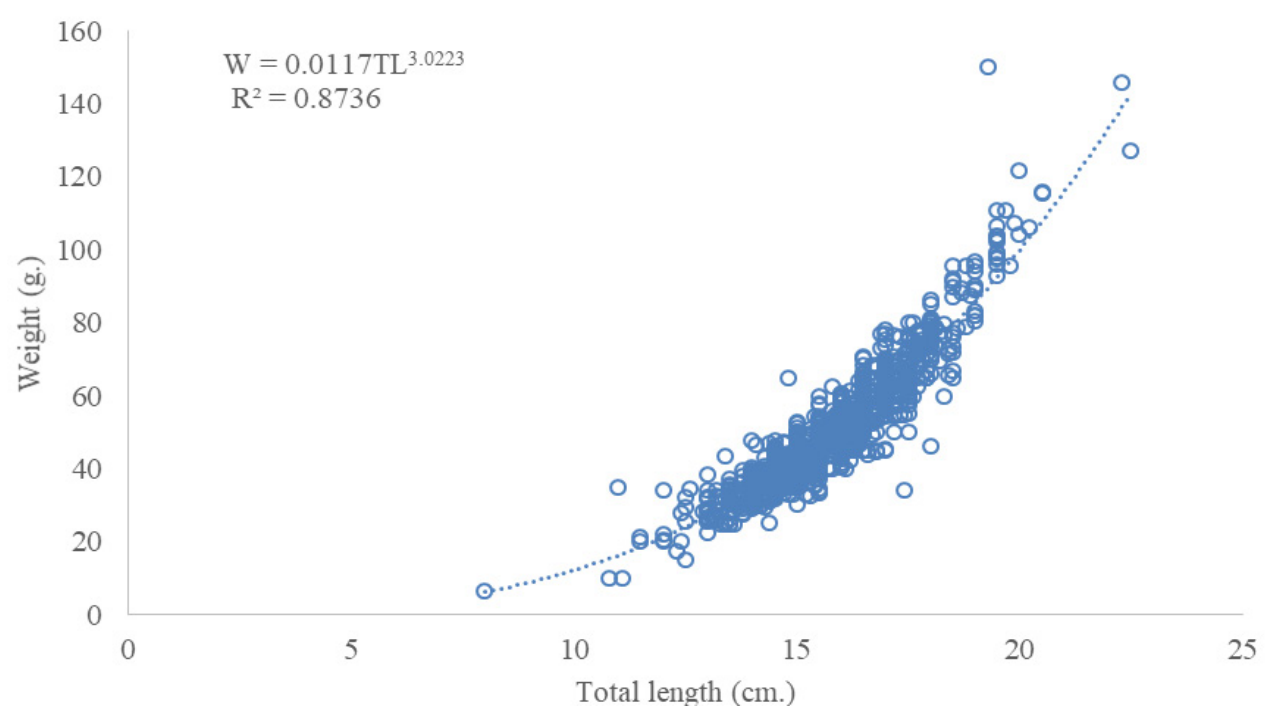

Figure 2 Length-weight relationship of total fish samples. 
The growth curves superimposed on monthly LFD are shown in Figure 3. Growth parameters from the von Bertalanffy growth formula for $J$. carouna were estimated as $\mathrm{L} \infty=22.28 \mathrm{~cm}$ and $\mathrm{K}=0.72$ year $^{-1}$. For these estimates through ELEFAN I, the index of goodness-of-fit of the growth curve (Rn) was 0.198. Principally, growth parameters are crucial factors in modelling aquatic ecosystems. There are many factors, such as environmental surroundings, food availability and hydrological conditions among different geographical and seasonal situations could influence the development of marine animals [22,23]. Unfortunately, there is no publication related to growth parameters of J. carouna. Therefore, the discussion on variation of growth parameter of this species is very limited. However, considering other Croaker species in Asian stock, the difference of growth parameters of same species but different habitats is published such as the L $\infty$ of Donkey croaker observed from Brunei Darsm $(29 \mathrm{~cm})$, Malaysia $(30 \mathrm{~cm})$ and India $(36 \mathrm{~cm})$ [24-26]. Phi prime was used as reliability index for the estimated growth parameters. The result suggested that the phi prime value of $J$. carouna was 2.55 which was similar to phi prime value from another study that investigated growth parameters of Dendrophysa russelii $(\varnothing=2.54)$ in the inner Gulf of Thailand [27].

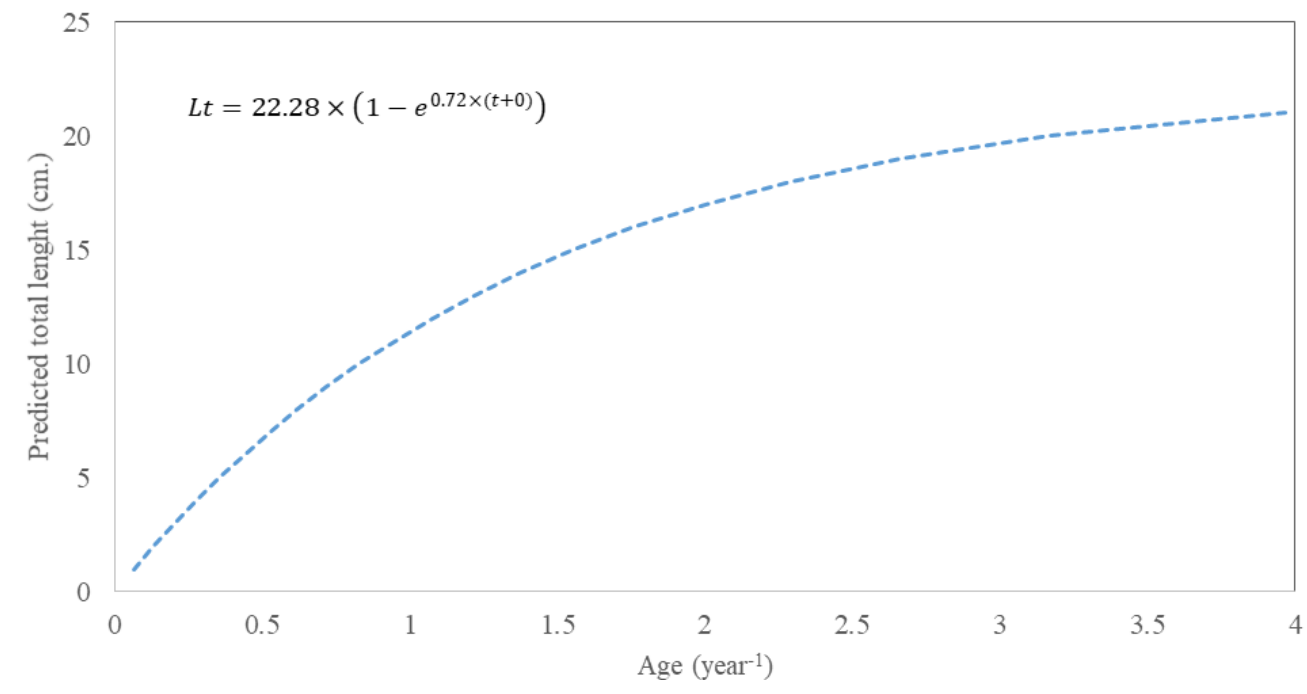

Figure 3 Predicted growth curve of J. carouna, based on Von Bertalanffy's growth function.

The length at $50 \%$ of maturity, $\mathrm{L}_{\mathrm{m}}$ of $J$. carouna was $15.3 \mathrm{~cm}$ (Figure 4), indicating it takes about 1.5 year to approach $\mathrm{L}_{\mathrm{m}}$. From the length converted catch curve, the total mortality $(\mathrm{Z})$ was 3.36 year $^{-1}$, with an $\mathrm{R}^{2}$-value $=0.9901$ and a confidence interval of the $\mathrm{Z}$-value were between 3.06 and 3.66. While natural mortality (M) was 1.62 year $^{-1}$, from the obtained values of $\mathrm{M}$ and $\mathrm{Z}$, therefore, the F-value was 1.74 year $^{-1}$ and the exploitation rate (E) was 0.52 (Figure 5A). From the probability of capture analysis (Figure 5B), LC ${ }_{50}$ of $J$. carouna was $15.12 \mathrm{~cm}$, which was slightly smaller than maturity size $(15.3 \mathrm{~cm})$. This finding indicated that the current fishing gears, several types of gillnets, caught slightly small fish are slightly overexploited because the fishermen catch small fish $\left(\mathrm{LC}_{50}<\mathrm{Lm}_{50}\right)$. 


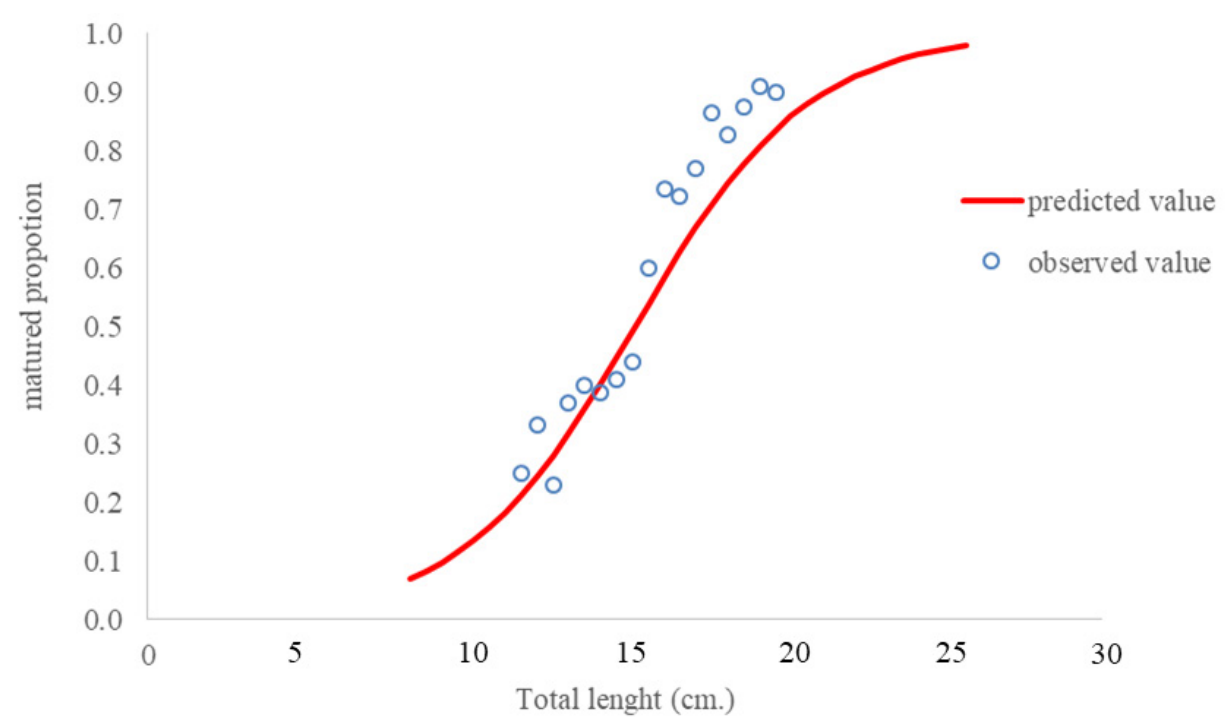

Figure 4 The length at $50 \%$ of maturity of $J$. carouna in Thasala coastal zone.
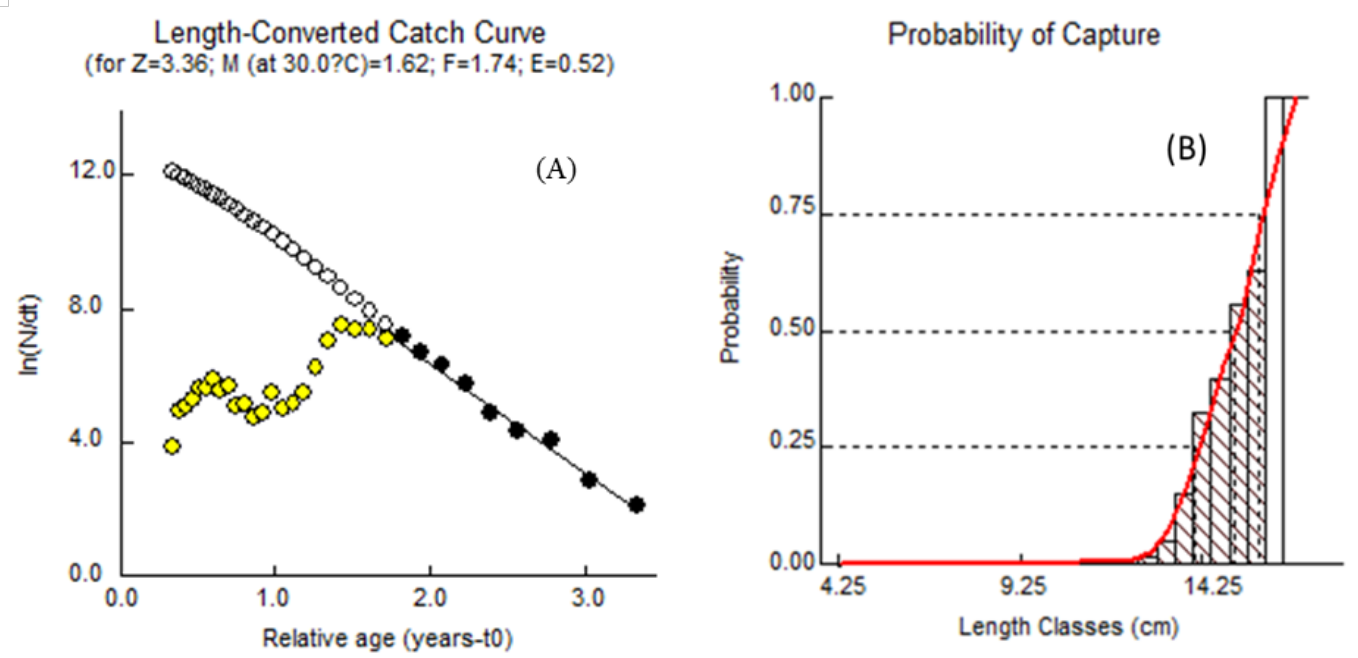

Figure 5 Length converted catch curve (A) and probability of capture (B) of J. carouna in Thasala coastal zone.

The recruitment was continuous with a single peak per year. The peak of recruitment was found in the seasonal-change periods that are the late summer season change to the early rainy season, between May and October (Figure 6A). A trend of over-exploitation was observed because the exploitation rate (0.52) was higher than optimum level $(E=0.5)$. The higher value of $E$ is indicative of over-fishing during the studied period. This assumption is based on [28], in which suitable yield is optimized when $F=M$, (i.e. when $\mathrm{E}$ is more than 0.50 the stock is generally considered to be over-fished). Although $\mathrm{E}_{\max }(0.703)$, from relative yield per recruited study, implied that fishers can increase fishing effort to J. carouna stock, the biological data disagreed with that way because the capture size is recently smaller than maturity length. Therefore, retaining fishing effort level but increase capture size, by increasing mesh size of 
gillnets seems to be better solution for Thasala fishing ground. Moreover, by increasing Lc, a yield of $J$. carouna will be increased and improve J. carouna stock in Thasala fishing ground. .
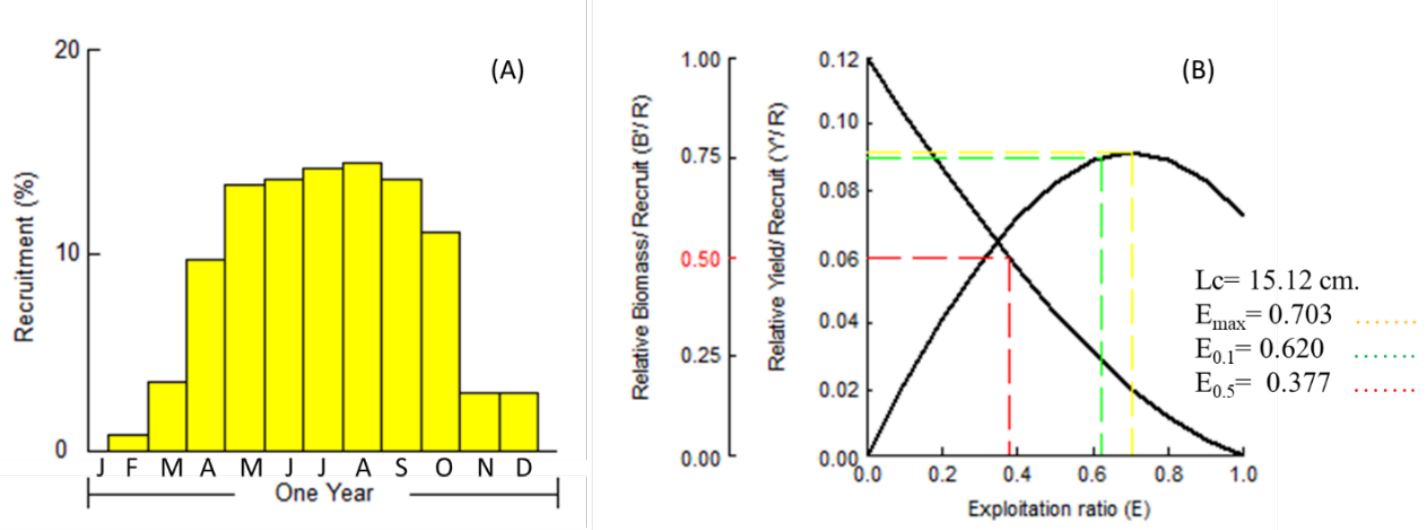

Figure 6 The percentage monthly recruitment (A) and Relative yield per recruitment (B) of J. carouna in Thasala coastal zone.

\section{Conclusions}

The findings of this study indicated that $J$. carouna population is currently faced with quite high fishing pressure situation in the area of study. The result from yield per recruitment suggested that the increase of captured fish size $(>15.3 \mathrm{~cm})$ by increasing local bottom gillnet mesh size, or operating fishing zone will be a better solution for J. carouna fishery. In addition to the best of our knowledge, as no academic publication currently exists on the population dynamics of $J$. carouna, the parameters obtained from this study are useful fundamental factors applicable in future fishing management trials as well as in technical restoration studies.

\section{Acknowledgements}

This research was granted by Institute of Research and Innovation (WU62214), Walailak University, Thailand. We are very grateful for the assistance of local fishermen during the field work. Thanks for their efforts for helping us to collect fish samples for a year period. We also thank undergraduate students, Kanyarat Chaomanop, Juraiwan Thongheet and Rodjanard Chansiri for their hands preparing the set of data for this project. This academic work was carried out by researcher teams under the research excellent center for coastal resources management with communal participation (CoRMaC), Walailak University.

\section{Reference}

[1] K Sasaki. Sciaenidae. Croakers (drums). In: KE Carpenter and VH Niem (Eds.). FAO species identification guide for fishery purposes. The living marine resources of the Western Central Pacific. Volume 5. Bony fishes part 3 (Menidae to Pomacentridae). FAO, Rome, 2001, p. 3117-74.

[2] JD Bell, RA Watson and Y Ye. Global fishing capacity and fishing effort from 1950 to 2012. Fish Fish. 2016; 18, 489-505.

[3] WE Ricker. Computation and interpretation of biological statistics of fish populations. Bull. Fish. Res. Bd. Canada 1975; 191, 382-92.

[4] FCJ Gayanilo, P Sparre and D Pauly. The FAO-ICLARM stock assessment tools (FiSAT) User's Guide. FAO Computerized Information Series (Fisheries), ICLARM Contribution No. 1048. ICLARM, Manila, 1995, p. 126. 
http://wjst.wu.ac.th

[5] JA Gulland. Fish Stock Assessment: A Manual of Basic Methods. Vol. I. FAO/Wiley Series on Food and Agriculture, Chichester, 1983, p. 223.

[6] US Amarasinghe and SS De Silva. Population dynamics of Oreochromis mossambicus and $O$. niloticus (Cichidae) in two reservoirs in Sri Lanka. Asian Fish. Sci. 1992; 5, 37-61.

[7] D Pauly. Some simple methods for the assessment of tropical fish stocks. FAO Fisheries Technical paper No. 234, 1983, p. 54.

[8] JL Munro and D Pauly. A simple method for comparing growth of fish and invertebrates. Fishbyte 1983; 1, 5-6.

[9] NS Mattson. 1997, Fish production and ecology in African small water bodies with emphasis on tilapia. Ph.D. Dissertation. Stockholm University, Stockholm, Sweden.

[10] D Pauly. Length-converted catch curves and the seasonal growth of fishes. Fishbyte 1990; 8, 33-8.

[11] FCJ Gayanilo and D Pauly. FAO-ICLARM stock assessment tools: Reference manual. FAO Computerized information series (Fisheries), ICLARM Contribution, FAO, Rome, 1997, p. 262.

[12] D Pauly and ML Soriano. Some Practical Extensions to Beverton and Holt's Relative Yield per Recruit Model. In: JL Maclean, LB Dizon and LV Hosillos (Eds.). The first Asian Fisheries Forum. Asian Fisheries Society, Manila, 1986, p. 491-5.

[13] C Ioannidou and JR O'Hanley. The importance of spatiotemporal fish population dynamics in barrier mitigation planning. Biol. Conserv. 2019; 231, 67-76.

[14] SE Tanner, AR Vieira, RP Vasconcelos, S Dores, M Azevedo, HN Cabral and JR Morrongiello. Regional climate, primary productivity and fish biomass drive growth variation and population resilience in a small pelagic fish. Ecol. Indic. 2019; 103, 530-41.

[15] KR Allen. Some observations on the biology of the trout (Salmo trutta) in Windermere. J. Anim. Ecol. 1938; 7, 333-49.

[16] KD Carlander. Handbook of freshwater fishery biology. Vol. I. Iowa State University Press, Iova, 1969, p. 752.

[17] SK Chakraborty. Length-weight relationship and biometric study on three species of sciaenids from Bombay waters. J. Indian Fish. Assoc. 1992; 22, 41-8.

[18] XH Wang, YS Qiu, GP Zhu, FY Du, DR Sun and SL Huang. Length-weight relationships of 69 fishes in the Beibu Gulf, northern South China sea. J. Appl. Ichthyol. 2011; 27, 959-61.

[19] MK Hena, MH Idris, AH Rajaee and MAM Siddique. Length-weight relationships of three fish species from a tropical mangrove estuary of Sarawak, Malaysia. J. Appl. Ichthyol. 2017; 33, 858-60.

[20] WS Chu JP Wang, YY Hou, YT Ueng and PH Chu. Length-weight relationships for fishes off the southwestern coast of Taiwan. Afr. J. Biotechnol. 2011; 10,3945-50.

[21] ES Haroun, K Akel and PK Karachle. The marine ichthyofauna of Egypt. Egypt. J. Aquat. Biol. 2017; 21, 81-116.

[22] Q Ma, S Tian, D Han, K Richard, C Gaoab and W Liu. Growth and maturity heterogeneity of three croaker species in the East China sea. Reg. Stud. Mar. Sci. 2021; 41, 101483.

[23] C Gao, Q Ma, S Tian, X Dai and R Kindong. Growth mortality and yield per recruitment of Small Yellow Croaker in offshore water of southern Zhejiang. Shuichan Xuebao 2019; 26, 925-37.

[24] AT Ahmad, MM Isa, MS Ismail and S Yusof. Status of demersal fishery resources of Malaysia. In: Proceedings of the $67^{\text {th }}$ WorldFish Center Conference. WorldFish Center, 2003, p. 83-135.

[25] GT Silvestre and LR Garces. Population parameters and exploitation rate of demersal fishes in Brunei Darussalam (1989-1990). Fish. Res. 2004; 69, 73-90.

[26] G Maheswarudu, GS Rao, P Rohit, P Laxmilatha, S Gosh and M Menon. Marine fisheries of Andhra Pradesh: A decadal analysis. Indian J. Fish. 2013; 60, 27-33.

[27] M Phettongkam and W Thasananulkit. The biology of Sciaena russelli (Cuvier et Valenciennes) in the inner Gulf of Thailand. In: Proceedings of the $3^{\text {rd }}$ Symposium on Marine Fisheries. Bangkok, Thailand, 1972, p. 1-18.

[28] JA Gulland. The Fish Resources of the Ocean. West Byfleet, Survey, Fishing News, FAO, 1971, p. 225. 